\title{
PROTEÇÃO DOS DIREITOS DOS IDOSOS NO JAPÃO SOB A ÓTICA DO DIREITO INTERNACIONAL DOS DIREITOS HUMANOS ${ }^{12}$ \\ PROTECTION OF THE RIGHTS OF THE ELDERLY IN JAPAN FROM THE PERSPECTIVE OF INTERNATIONAL HUMAN RIGHTS LAW
}

\section{Larissa Sonoda Dantas ${ }^{3}$ \\ Lilian Yamamoto ${ }^{4}$}

Resumo Este artigo analisa o status atual dos direitos dos idosos no Japão, na perspectiva do direito internacional dos direitos humanos. Discute o status dos idosos enquanto um grupo que precisa de proteções específicas e avalia seus direitos no sistema internacional dos Direitos Humanos. Ademais, faz uma revisão do desenvolvimento do direito dos idosos no Estado japonês e uma análise da proteção de seus direitos no país a partir dos principais instrumentos internacionais de direitos humanos.

Palavras Chave: Direitos Humanos, Japão, Idosos, Nações Unidas, Tratados

Abstract This article analyses the current status of elderly rights in Japan from the perspective of international Human Rights. It discusses the status of older people as a group that needs specific protections and evaluates the existence of their rights in the International Human Rights System. In addition, it reviews the development of the elderly rights in the Japanese

1 Artigo submetido em 13/01/2020 e aprovado em 21/04/2020.

2 A pesquisa para a elaboração deste artigo foi realizada com apoio da Coordenação de Aperfeiçoamento de Pessoal de Nível Superior (Capes).

3 Mestranda do Programa de Pós-Graduação em Língua, Literatura e Cultura Japonesa (PPGLLCJ) da Faculdade de Filosofia, Letras e Ciências Humanas (FFLCH) da Universidade de São Paulo, São Paulo, Brasil; larissa.s.dantas@usp.br (ORCID iD: https://orcid.org/0000-0003-2430-3607).

4 Professora colaboradora do Programa de Pós- Graduação em Língua, Literatura e Cultura Japonesa. (PPGLLCJ), da Faculdade de Filosofia, Letras e Ciências Humanas (FFLCH) da Universidade de São Paulo (USP), São Paulo, Brasil; Doutora em Direito Internacional, Universidade Kanagawa, Japão; liukami2014@gmail.com (ORCID iD: https://orcid.org/0000-0002-8304-9509). 
State and analyses their protection from the perspective of the main international Human Rights instruments.

Keywords: Human Rights, Japan, Elderly, United Nations, Treaties

\section{Introdução}

Os Direitos Humanos (DHs) são considerados pelas Nações Unidas como universais e inerentes a todos os seres humanos, isto é, são aplicáveis em qualquer lugar ou nação do mundo e para todos os seres humanos "independentemente de raça, sexo, nacionalidade, etnia, idioma, religião ou qualquer outra condição" (NAÇÕES UNIDAS BRASIL, [s.d.]). Apesar de serem inerentes a todos, há grupos de pessoas que foram reconhecidos na comunidade internacional por possuírem maior vulnerabilidade de sofrerem violações de seus direitos e, por esta razão há tratados internacionais referentes a proteções de grupos específicos como mulheres e crianças ${ }^{5}$.

O entendimento do idoso ${ }^{6}$ como um ator que necessita de direitos e políticas específicas para garantir sua proteção e bem-estar é um fenômeno relativamente recente na perspectiva dos Direitos Humanos. Durante muito tempo a gestão da velhice foi considerada como "uma questão da esfera privada e familiar"(DEBERT, 1992, p. 33) e sua transformação em uma questão pública deriva em grande medida das mudanças sociais e demográficas que ocorreram globalmente. Com fenômeno do envelhecimento populacional - aumento da longevidade somado ao declínio acentuado nas taxas de fertilidade - os idosos passaram a corresponder a uma parcela cada vez maior da população ${ }^{7}$, o que tornou mais proeminente suas demandas nas agendas públicas globais. Neste contexto, o Japão se destaca por ser o país com a maior população idosa ${ }^{8}$ no mundo - as pessoas com mais de 65 anos já representam 27\% da população (JAPAN. NIPSSR, 2019).

O presente artigo irá analisar a evolução da proteção dos direitos dos idosos no Japão sob a perspectiva do sistema internacional de Direitos Humanos dentro do sistema das Nações Unidas. Abordará inicialmente o status dos direitos dos idosos nos instrumentos de DHs, na sequência discorrerá sobre o desenvolvimento dos direitos dos idosos no Japão e, por fim, apresentará uma análise das proteções e violações de direitos dos idosos no Japão.

5 As principais convenções de direitos de grupos particulares podem ser acessadas em $<$ https://www. ohchr.org/EN/ProfessionalInterest/Pages/CoreInstruments.aspx> Acesso em: 12/11/2019.

6 Este artigo utilizará os termos "idoso" e "pessoas mais velhas" para indicar indivíduos ou grupo de pessoas com idade igual ou superior a 60 ou 65 anos. Estes serão os termos utilizados na tradução de expressões do inglês como: "elderly persons, aged, older person". Importante ressaltar que no sistema das Nações Unidas não há uma definição única de idoso, em geral adota-se 60 anos para países considerados em desenvolvimento e 65 para países desenvolvidos.

7 De acordo com relatório das Nações Unidas a população acima de 60 anos é a que mais tem crescido, com uma taxa de crescimento médio global de 3\% ao ano, representando, em 2017, $13 \%$ da população mundial (DESA, 2017).

8 No Japão são idosas as pessoas com idade igual ou superior a 65 anos. 


\section{Os Direitos Humanos Internacionais e os Direitos dos Idosos}

Atualmente, não há um tratado internacional específico de proteção aos direitos dos idosos. Mas como os DHs são universais e aplicáveis a todos sem distinção, os idosos desfrutam de proteções gerais nos instrumentos existentes e possuem ainda algumas proteções específicas em cláusulas particulares de tratados e convenções internacionais vinculantes 9 . Desde 1982, há instrumentos não vinculantes sobre os direitos dos idosos que também são relevantes ${ }^{10}$.

Com relação aos tratados vinculantes, a primeira referência relevante aos direitos dos idosos aparece na Declaração Universal dos Direitos Humanos (DUDH $)^{11}$ de 1948 no artigo 25 que dispõe que "Toda a pessoa tem direito a um nível de vida suficiente (...) e tem direito à segurança (...) na velhice ou noutros casos de perda de meios de subsistência por circunstâncias independentes da sua vontade" (NAÇÕES UNIDAS, 1948). No Pacto Internacional de Direitos Civis e Políticos (PIDCP) o artigo 26 que declara que "Todas as pessoas são iguais perante a lei e têm direito, sem discriminação alguma" (ICCPR, 1966) é considerado o mais importante para esta questão. Este artigo tem sido acionado para estender aos idosos direitos específicos, principalmente para garantia do direito a benefícios de seguridade social. (RODRIGUEZ-PINZÓN, 2003).

Um dos tratados mais importantes para a população idosa é o Pacto Internacional dos Direitos Econômicos, Sociais e Culturais - PIDESC (CESCR, 1966). Isto porque, $p$ ara além das proteções gerais, Comitê sobre Direitos Econômicos, Sociais e Culturais - (CESCR) adotou em 1995 o Comentário Geral número 6 no qual discorre sobre como PIDESC deve ser aplicado no contexto dos idosos ${ }^{12}$. Ademais,

9 Um instrumento é considerado vinculante quando, após sua ratificação, os Estados se comprometem legalmente em cumprir suas disposições. Com relação aos tratados de direitos humanos, os Estados devem enviar relatórios regulares aos comitês de monitoramento dos respectivos pactos. Uma lista dos comitês pode ser encontrada em $<$ https://www.ohchr.org/en/hrbodies/Pages/HumanRightsBodies. aspx>. Acesso em 29/11/2019.

10 Há uma discussão no sistema internacional sobre a necessidade de um tratado específico para os direitos dos idosos. Aqueles que são a favor argumentam, entre outras coisas, que os documentos vinculantes são mais eficazes no monitoramento dos direitos e no regulamento do comportamento dos Estados. Os que discordam, entendem que há instrumentos suficientes para estes fins e que o caráter não vinculante permite que se elaborem documentos mais abrangentes e diretivos. Para fins deste artigo, não é necessário um aprofundamento neste tema, apenas separaremos os tipos de instrumentos em função de sua natureza. Para maiores informações nesta questão ver (FREDVANG; BIGGS, 2012)

11 Embora a declaração não seja um tratado, há autores que argumentam que seu conteúdo já se tornou costumeiro e, portanto, legalmente vinculante (FREDVANG; BIGGS, 2012)

12 As interpretações mencionadas no comentário são: artigo 3: no qual o comitê expressa preocupação com as mulheres que tenham cuidado da família durante a vida e, em função disso, e não tenham contribuído para seguridade social; artigos 6 a 8: para garantir o direito dos idosos ao trabalho e preparação para aposentadoria; artigo 9: garantia de seguridade social para os idosos, incluindo os mais vulneráveis; artigo 10: apoiar famílias nos cuidados dos idosos e prover assistência àqueles que vivem 
assumiu para si a responsabilidade de "monitorar a implementação de proteção internacional aos direitos dos idosos" (RODRIGUEZ-PINZÓN, 2003, p. 954). Outro instrumento relevante para este grupo é a Convenção sobre os Direitos das Pessoas com Deficiência (CRPD, 2006 sigla em inglês). A convenção não traz uma definição específica sobre deficiência e, por isso, muitos de seus artigos podem ser interpretados para a proteção dos direitos dos idosos (KANTER, 2009). Finalmente, as convenções sobre a Eliminação de Todas as Formas de Discriminação contra a Mulher (CEDAW, 1979 sigla em inglês) e Sobre a Proteção dos Direitos de Todos os Trabalhadores Migrantes e dos Membros das suas Famílias (1990) em seus artigos 11 e 7, respectivamente, mencionam a idade como critério para igualdade de direitos entre homens e mulheres.

O monitoramento desses direitos é realizado pelos Comitês responsáveis pelos pactos por meio de relatórios periódicos enviados pelos Estados partes. Contudo, Judge (2008) e Fredvang e Biggs (2012) apontam que pode haver uma lacuna de proteção aos idosos, uma vez que muitos países não fazem referências explícitas à situação deste grupo e que os comitês responsáveis tampouco orientam os países a fazê-lo.

Com relação aos instrumentos não vinculantes, em 1982, a Assembleia das Nações Unidas adotou o Plano de Ação Internacional de Viena sobre o Envelhecimento, com 62 pontos e recomendações acerca da saúde e nutrição, não segregação dos idosos, proteção de consumidores idosos, habitação, família, bem-estar social, incluindo assistência residencial aos idosos, segurança de renda e emprego, educação entre outros. (FREDVANG; BIGGS, 2012; NAÇÕES UNIDAS BRASIL, [s.d.]). Em 2002, foi realizada a Segunda Assembleia Mundial das Nações Unidas sobre o Envelhecimento, em Madri, na qual foi adotada a Declaração Política e o Plano de Ação Internacional sobre o Envelhecimento de Madri (MIPAA, 2002 sigla em inglês). O plano é uma ampliação das recomendações do Plano de Viena (1982), com grande foco nos direitos humanos e no desenvolvimento de políticas para o envelhecimento no século XXI. As recomendações são organizadas em três orientações prioritárias (i) pessoas idosas e o desenvolvimento, (ii) promoção da saúde e bem-estar na velhice e (iii) criação de ambiente propício e favorável. O MIPAA possui 16 subtemas e 22 objetivos para a realização dos mesmos. "O objetivo do Plano de Ação consiste em garantir que, em todas as partes, a população possa envelhecer com segurança e dignidade e que os idosos possam continuar participando em suas respectivas sociedades como cidadãos com plenos direitos."(MIPAA, 2002, p. 29) e está organizado de forma a oferecer um guia prático para formulação de políticas públicas. "Desde sua adoção o

sozinhos; artigo 11: recomendações para padrão de vida adequado na velhice que inclua alimentação, abrigo, vestimenta, assistência medica e social; artigo 12: direito à saúde física e mental como foco em prevenção; artigo 13 a 15 direito à educação e cultura com duas abordagens distintas, do direito dos idosos à educação e do compartilhamento de suas experiências com as gerações mais novas.(CESCR, 1995) 
MIPAA tem guiado políticas domésticas e os diálogos internacionais sobre os direitos das pessoas idosas"(FREDVANG; BIGGS, 2012, p. 12) ${ }^{13}$.

O monitoramento da implementação do MIPAA é de responsabilidade da Comissão para o Desenvolvimento Social das Nações Unidas. O monitoramento ocorre a cada 5 anos e um relatório global é consolidado a partir de relatórios regionais ${ }^{14}$.

\section{Os Direitos dos Idosos na Legislação Japonesa}

O Japão possui uma das maiores expectativas de vida -80.75 anos para homens e 86.99 anos para mulheres (JAPAN. CABINET OFFICE, 2017, p. 5) - e a maior proporção de idosos no mundo em sua população. Esta seção abordará os direitos dos idosos no Japão a partir de uma revisão histórica das principais políticas e legislações referentes a este tema no país.

Uma das primeiras proteções estabelecidas para as pessoas idosas no Japão foi a criação do sistema previdenciário. O sistema de previdência para funcionários públicos e privados foi instituído no Japão na primeira metade século XX - 1923 e 1942, respectivamente (USUI; PALLEY, 1997, p. 378). No período do pós- Segunda Guerra Mundial, o Japão ampliou esta proteção com a Lei de Reforma do Sistema de Pensões dos Trabalhadores ${ }^{15}$ (1954) - para trabalhadores autônomos e agrícolas - e com o estabelecimento de um Sistema Universal de Seguros de Saúde e Previdência ${ }^{16}$ (1961) que cobria todos os cidadãos japoneses, independente de sua ocupação ou renda. Importante ressaltar, contudo, que até 1982 - quando o país ratificou a Convenção das Nações Unidas relativa ao Estatuto dos Refugiados - estrangeiros não podiam ingressar no sistema de previdência nacional.

Em função de um grande crescimento econômico no país, durante as décadas de 1960 e 1970, houve uma expansão dos benefícios de seguridade social para os idosos. Em 1963, foi promulgada a Lei de Serviço de Bem-Estar Social para os $\operatorname{Idosos}^{17}$. A lei tem como objetivo regular as políticas de bem-estar para as pessoas com idade superior a 65 e atribui ao Estado japonês a responsabilidade da "manutenção de renda, saúde, serviços sociais e oportunidades de

13 Um resumo elaborado pelas ONU contendo os principais tratados e como eles se relacionam ao MIPAA pode ser encontrado em $<$ https://social.un.org/ageing-working-group/documents/Table $\% 20 \mathrm{HR} \% 20$ \&\%20MIPAA\%20-\%20April\%202011.pdf>. Acesso em 01/12/2019.

14 Mais informações sobre o processo de monitoramento do plano em: https://www.un.org/development/ desa/ageing/3rdreview-mipaa.html. Acesso em 28/11/2019.

15 Revision of Employees' Pension Insurance Act

16 Universal Coverage in Public Pension and Health Insurance

17 Act on Social welfare for the Elderly 
emprego"(HASHIMOTO, 2009, p. 37) para essas pessoas. Cabe destacar que essa legislação priorizava idosos de baixa renda e que não possuíssem familiares que pudessem se encarregar de seu cuidado. Embora fosse uma importante política para atender aos idosos desassistidos, seus critérios de elegibilidade tornavam o sistema praticamente inacessível para famílias de classe média. Esta premissa refletia a percepção de que o cuidado dos idosos era responsabilidade da família - em particular das mulheres, como filhas e noras, por exemplo (ETO, 2001). No âmbito da saúde, também houve aumento de benefícios durante a década de 1970 . O governo eliminou todas as taxas dos serviços de saúde para os idosos com idade superior a 70 anos, tornando o serviço gratuito com o "Plano de Tóquio"18. Essa política, contudo, durou pouco.

Em 1982, o governo promulgou a Lei de Saúde para Idosos ${ }^{19}$, que cessou a gratuidade dos serviços médicos na tentativa de reduzir os custos com saúde ${ }^{20}$. O país passava por grandes transformações sociais nesta época, a proporção de idosos crescia em um ritmo muito acelerado ${ }^{21}$, a proporção de famílias nucleares aumentava rapidamente e o papel social das mulheres estava mudando, com o aumento de sua escolaridade e entrada no mercado de trabalho (ETO, 2001). Neste cenário, a "socialização do cuidado", isto é, "a ideia de que o cuidado com idosos não deveria ser responsabilidade apenas da família, mas de toda a sociedade, gradualmente ganhou popularidade na mídia de massas e o público passou a reconhecer a seriedade do problema". (Asahi shimbun, 6.9.1988, p. 35 in ETO, 2001, p.22). Desta maneira, em 1989, o governo japonês instituiu um novo plano para a promoção da saúde, cuidado e Bem-Estar do idoso, conhecido como Plano Ouro, ${ }^{22}$ que foi revisado em 1994 e 1999. Com o plano, o governo procurou reduzir os custos com os cuidados dos idosos ao construir uma infraestrutura nacional para oferecer esses cuidados em programas e instituições de base comunitárias e eliminou os critérios de renda e cuidados familiares para acesso aos serviços. No ano 2000, o governo japonês, procurando aumentar a eficiência do atendimento aos idosos, unificou os sistemas de saúde e de bem-estar social para idosos e instituiu o Sistema de Seguro de Cuidados de Longa Duração

18 Tokyo Plan - Introduction of free medical care for the elderly

19 Health Care for the Aged Law

20 "Em 1981, a população com 70 anos ou mais constituía 5,9\% da população total, mas representava $21,2 \%$ do custo total dos cuidados médicos. Os custos de cuidados de saúde para os idosos (70 anos ou mais) cresceu 466\% de 1973 a 1986.”(USUI; PALLEY, 1997, p.370)

21 O Japão levou menos de 30 anos para dobrar a taxa de idosos de 7\% em 1970 para 14\% em 1994. Outros países industrializados levaram muito mais tempo neste processo a França levou 130 anos, Suécia 85 anos e Estados Unidos 75 anos (USUI; PALLEY, 1997)

22 Gold Plan 
$(\mathrm{SSCLD})^{23}$. Este é um sistema bastante abrangente que inclui em seus serviços demandas de saúde, cuidado, alimentação, habitação e transporte de maneira mais eficiente do que os anteriores.

Ademais das medidas relacionadas à saúde e assistência social, em 1995, o governo instituiu a Lei Básica sobre Medidas para a Sociedade em Envelhecimento ${ }^{24}$, para preparar o país para uma sociedade em envelhecimento. A lei contém diretrizes para implementação de políticas para o envelhecimento no país em 6 pilares - trabalho e renda; saúde e bem-estar social; aprendizado e participação social; habitação; pesquisa e implementação de políticas e sua implementação da lei é monitorada anualmente por meio de relatórios. Dentro das políticas para idosos, uma das frentes com maior destaque no país é a de empregabilidade. Desde 1971, o governo possui leis com este fim, como a Lei sobre a Estabilização do Emprego de Idosos ${ }^{25}$, que foi revisada diversas vezes até 2012, e o Centro de Recursos Humanos Prateado (1980) - rede nacional de agências de empregos para pessoas com mais de 60 anos.

Apesar de tantas políticas para população idosa, novos desafios se apresentaram para esta sociedade "super-envelhecida". A quantidade de pessoas com algum grau de demência no país era 4,62 milhões em 2012, cerca de 1 em 7 idosos (JAPAN. CABINET OFFICE, 2017, p. 17) e, no mesmo ano, o governo instituiu um plano para resolver este problema, o Plano Laranja ${ }^{26}$ - revisado em 2015. O plano estabelece novos programas de diagnóstico, tratamento e cuidado para pessoas com demência (JAPAN. NIPSSR, 2019, p. 43). Para responder ao aumento de casos de violência contra idosos, em 2005, o governo promulgou a Lei sobre a Prevenção de Violência contra Idosos ${ }^{27}$ que procura prevenir, identificar e proteger os idosos de abusos por meio de programas de conscientização, denúncia e compartilhamento de informações (JAPAN. NIPSSR, 2019, p. 49). Finalmente, talvez a questão mais preocupante com os idosos no país é a pobreza. O índice de pobreza entre os idosos é o que mais cresce no Japão, principalmente entre mulheres e idosos acima de 75 anos - uma em 4 mulheres com idade superior a 75 anos está abaixo da linha da pobreza, índice superior à média dos países da OCDE. Apesar dos esforços do país, o Japão ainda não conseguiu solucionar adequadamente este problema. (OCDE, 2017).

23 Long-Term Care Insurance System. Para maiores informações sobre as políticas de saúde e bem-estar para idosos no Japão ver: (ASIA PACIFIC OBSERVATORY, 2018; MINISTRY OF HEALTH LABOUR AND WELFARE OF JAPAN, 2016, p. 4; USUI; PALLEY, 1997, p. 372-377).

24 Basic Law on Measures for the Aging Society. disponível em: $<$ https://www8.cao.go.jp/kourei/english/ measure/kihon-e.html> Acesso em 29/11/2019.

25 Act on Stabilization of Employment of Elderly Persons

26 Orange Plan

27 Act on the Prevention of Elder Abuse 
Tabela 1: Resumo das principais medidas para idosos no Japão

\begin{tabular}{|c|c|c|}
\hline Ano & Lei/política & Detalhes \\
\hline 1923 & $\begin{array}{l}\text { Consolidação das previdên- } \\
\text { cias públicas dos Militares } \\
\text { e funcionários públicos }\end{array}$ & Consolida as previdências. \\
\hline 1942 & $\begin{array}{l}\text { Lei de seguro de pen- } \\
\text { são dos trabalhadores }\end{array}$ & $\begin{array}{l}\text { Estipula que a idade de aposentado- } \\
\text { ria para homens é } 56 \text { anos - mulhe- } \\
\text { res não estavam incluídas. }\end{array}$ \\
\hline 1954 & $\begin{array}{l}\text { Lei de Reforma do Sistema de } \\
\text { Pensões dos Trabalhadores }\end{array}$ & $\begin{array}{l}\text { Aposentadoria para homens passa } \\
\text { de } 56 \text { para } 60 \text { anos e mulhe- } \\
\text { res - agora incluídas - } 55 \text { anos. }\end{array}$ \\
\hline 1961 & $\begin{array}{l}\text { Sistema Universal de Segu- } \\
\text { ros de Saúde e Previdência }\end{array}$ & $\begin{array}{l}\text { Cobertura universal de saúde e } \\
\text { previdência para a população. }\end{array}$ \\
\hline 1963 & $\begin{array}{l}\text { Lei de Serviço de Bem-Es- } \\
\text { tar Social para os Idosos }\end{array}$ & $\begin{array}{l}\text { Atribui responsabilidades para as dife- } \\
\text { rentes instâncias administrativas, asi- } \\
\text { los são criados e clubes de idosos são } \\
\text { incentivados com recursos do governo. }\end{array}$ \\
\hline 1971 & $\begin{array}{l}\text { Lei sobre a estabilização } \\
\text { do emprego de idosos }\end{array}$ & $\begin{array}{l}\text { Encoraja participação dos ido- } \\
\text { sos nos empregos. }\end{array}$ \\
\hline 1973 & Plano de Tóquio & $\begin{array}{l}\text { Cuidados médicos para pessoas com } \\
\text { mais de } 70 \text { anos tornam-se gratuitos. }\end{array}$ \\
\hline 1976 & $\begin{array}{l}\text { Revisão da lei sobre estabili- } \\
\text { zação do emprego de idosos }\end{array}$ & $\begin{array}{l}\text { Atribui meta não vinculante } \\
\text { de } 6 \% \text { do total de trabalhado- } \\
\text { res ter } 65 \text { anos ou mais. }\end{array}$ \\
\hline 1980 & $\begin{array}{l}\text { Início do Centro de Recur- } \\
\text { sos Humanos Prateado }\end{array}$ & $\begin{array}{l}\text { As agências passam a rece- } \\
\text { ber subsídios do governo. }\end{array}$ \\
\hline 1982 & Lei de Saúde para Idosos & $\begin{array}{l}\text { Ajuste no financiamento das despesas } \\
\text { médicas dos idosos, fim da gratuidade. }\end{array}$ \\
\hline
\end{tabular}




\begin{tabular}{|c|c|c|}
\hline Ano & Lei/política & Detalhes \\
\hline 1985 & $\begin{array}{l}\text { Revisão da Lei de Seguro } \\
\text { de Pensão dos Empregados }\end{array}$ & $\begin{array}{l}\text { Idade de aposentadoria passa de } 60 \text { para } \\
65 \text { a homens e de } 55 \text { para } 60 \text { a mulheres. }\end{array}$ \\
\hline 1986 & $\begin{array}{l}\text { Nova Lei de Estabilização } \\
\text { do Emprego para Idosos }\end{array}$ & $\begin{array}{l}\text { Revisão de medidas para empregabi- } \\
\text { lidade de idosos e gestão dos Centros } \\
\text { de Recursos Humanos Prateados. }\end{array}$ \\
\hline 1989 & Plano Ouro & $\begin{array}{l}\text { Aumenta infraestrutura de cui- } \\
\text { dado e bem-estar para idosos. }\end{array}$ \\
\hline 1990 & $\begin{array}{l}\text { Revisão da Lei de Estabiliza- } \\
\text { ção do Emprego para Idosos }\end{array}$ & $\begin{array}{l}\text { Estabelece possibilidade de reemprego } \\
\text { para os aposentados que desejarem. }\end{array}$ \\
\hline 1994 & $\begin{array}{l}\text { Revisão da Lei de Seguro } \\
\text { de Pensão dos Empregados }\end{array}$ & $\begin{array}{l}\text { Idade de aposentadoria passa de } \\
60 \text { para } 65 \text { a todas as pessoas. }\end{array}$ \\
\hline 1994 & $\begin{array}{l}\text { Revisão da Lei de Estabiliza- } \\
\text { ção do Emprego para Idosos }\end{array}$ & Introduz sistema de pós-aposentadoria. \\
\hline 1995 & $\begin{array}{l}\text { Lei Básica sobre Medi- } \\
\text { das para a Sociedade } \\
\text { em Envelhecimento }\end{array}$ & $\begin{array}{l}\text { Diretrizes para implementação de } \\
\text { políticas para o envelhecimento. }\end{array}$ \\
\hline 2000 & $\begin{array}{l}\text { Formulação do Plano Ouro } \\
21 \text { / Promulgação do Sis- } \\
\text { tema de Seguro de Cuida- } \\
\text { dos de Longa Duração }\end{array}$ & $\begin{array}{l}\text { Mudanças na gestão dos serviços } \\
\text { e introdução do Sistema de Seguro } \\
\text { de Cuidados de Longa Duração. }\end{array}$ \\
\hline 2000 & $\begin{array}{l}\text { Revisão da Lei de Estabiliza- } \\
\text { ção do Emprego para Idosos }\end{array}$ & $\begin{array}{l}\text { Extensão da idade obrigatória de apo- } \\
\text { sentadoria - se o trabalhador desejar. }\end{array}$ \\
\hline 2005 & $\begin{array}{l}\text { Lei sobre prevenção } \\
\text { de abuso de idosos }\end{array}$ & $\begin{array}{l}\text { Define o que é Abuso de Idosos e esti- } \\
\text { pula obrigação de denunciar violações. }\end{array}$ \\
\hline 2008 & $\begin{array}{l}\text { Sistema de atendimento } \\
\text { médico para idosos com } \\
75 \text { anos ou mais }\end{array}$ & $\begin{array}{l}\text { Sistema independente de saúde } \\
\text { é criado para esta população. }\end{array}$ \\
\hline
\end{tabular}




\begin{tabular}{|l|l|l|}
\hline Ano & Lei/política & Detalhes \\
\hline 2011 & $\begin{array}{l}\text { Revisão da Lei de Garantia } \\
\text { do Abastecimento Estável } \\
\text { de Moradias para Idosos }\end{array}$ & $\begin{array}{l}\text { Promove habitações adequadas } \\
\text { e com serviços para idosos. }\end{array}$ \\
\hline 2012 & $\begin{array}{l}\text { Revisão da Lei de Estabiliza- } \\
\text { ção do Emprego para Idosos }\end{array}$ & $\begin{array}{l}\text { Revisão para garantir acesso a tra- } \\
\text { balho para trabalhadores com } \\
\text { idade superior a 65 anos. }\end{array}$ \\
\hline 2013 & $\begin{array}{l}\text { Lei Básica de Contra- } \\
\text { medidas de Desastres }\end{array}$ & $\begin{array}{l}\text { Novos programas de diagnos- } \\
\text { tico, tratamento e cuidado para } \\
\text { pessoas com demência. }\end{array}$ \\
\hline 2015 & $\begin{array}{l}\text { Estratégia Abrangente - Rea- } \\
\text { lizar Comunidade Amiga } \\
\text { da Idade e da Demência } \\
\text { (Novo Plano Laranja }\end{array}$ & $\begin{array}{l}\text { lista de pessoas que requerem assis- } \\
\text { tência especial durante um desastre } \\
\text { ou quando houver risco de desastre } \\
\text { (idosos, pessoas com deficiência etc). }\end{array}$ \\
\hline
\end{tabular}

Fonte: elaborada a partir de (MHLW JAPAN, 2014, p. 24)

\section{Análise dos direitos dos idosos à luz dos direitos humanos ${ }^{28}$}

Após a revisão dos direitos dos idosos no âmbito dos Direitos Humanos Internacionais e no Japão, interessa compreender como a comunidade internacional, representada pelas entidades das Nações Unidas, percebe o status de proteção dos direitos dos idosos no Japão. Esta análise será realizada a partir dos relatórios periódicos enviados pelo governo japonês aos comitês dos tratados internacionais mais relevantes acerca dos direitos dos idosos e do relatório sobre a implementação do MIPAA $^{29}$. Importante notar que, como não há uma convenção internacional

28 Ver anexo 1 uma tabela resumo dos principais artigos internacionais seguidos pelo governo do Japão.

29 Serão avaliadas as versões mais recentes dos documentos: a) relatórios periódicos; b) observações finais; c) lista de questões e d) respostas à lista de questões. Para uma lista detalhada de todos os pactos ratificados pelo Japão ver $<$ https://www.mofa.go.jp/files/000175306.pdf > Acesso em: 15/11/2019 e $<$ https://www.ohchr.org/EN/Countries/AsiaRegion/Pages/JPIndex.aspx > Acesso em: 15/11/2019. 
específica sobre os direitos da população idosa, os Estados não submetem relatórios periódicos sobre este tema a um único comitê.

A partir da perspectiva do instrumento mais abrangente dos direitos dos idosos, o MIPAA ${ }^{30}$, no relatório referente à terceira rodada de monitoramento do plano, o Japão possui destaques positivos nos três eixos do plano: (i) com mecanismos de redistribuição de gênero em seu sistema de seguridade social $^{31}$; (ii) a introdução e reforma do SSCLD que fortaleceu a base comunitária do sistema; (iii) no atendimento à demanda por habitação e transporte amigáveis para idosos pelo o SSCLD. A comissão relatora (ESCAP: Comissão Económica e Social para a Ásia e o Pacífico) cita o Japão como um exemplo na implementação de políticas públicas para idosos com planos de ação e mecanismos de monitoramento interno - por exemplo, os relatórios anuais sobre a Lei Básica sobre Medidas para a Sociedade em Envelhecimento.

No terceiro relatório periódico (JAPAN, 2011) sobre o Pacto Internacional dos Direitos Econômicos, Sociais e Culturais (PIDESC), o governo japonês destacou como medidas para os idosos: a revisão do SSCLD, a Lei sobre a Prevenção de Violência contra Idosos de $2005^{32}$, a revisão da Lei sobre a Estabilização do Emprego de Idosos (2006); as mudanças nas regras da previdência de 2004 - em caso de divórcio, a aposentadoria é dividida entre o casal; a Lei de Saúde para o Idoso - com aconselhamento nutricional; e a Lei de Vida Estável para os Idosos ${ }^{33}$ - que contém disposições para facilitar o aluguel e moradias adequadas às necessidades dos idosos (art. 11 do PIDESC). Nos comentários sobre o relatório, o comitê apresentou preocupações com a desigualdade de renda entre homens e mulheres no sistema de aposentadoria e com a incidência de pobreza entre os idosos que não estão incluídos no sistema de previdência do país, principalmente entre as mulheres (CESCR, 2013).

No sexto relatório periódico (JAPAN, 2012) sobre o Pacto Internacional de Direitos Civis e Políticos (PIDCP), a principal questão relativa às pessoas idosas é no artigo 26, sobre a exclusão de Coreanos Zainichi ${ }^{34}$ do sistema de aposentadoria. Isto ocorre porque

Importante destacar que o MIPAA não é um tratado vinculante, por esta razão o Japão o adotou ao participar da Assembleia em 2012. Para maiores informações ver: https://www.un.org/en/events/ pastevents/pdfs/Madrid_plan.pdf Acesso em: 15/11/2019.

30 Para maiores informações ver o relatório regional disponível em $<$ https://www.un.org/development/ desa/ageing/wp-content/uploads/sites/24/2017/02/escap-mipaa-report2017.pdf > Acesso em 21/11/2019.

31 O relatório não especifica o mecanismo citado, mas destaca a presença de licença maternidade no sistema japonês.

32 Segundo o governo, com a promulgação da lei, houve um aumento de denúncias, contribuindo para punição e prevenção de novas ocorrências.

33 Act of Stable Living for the Elderly

34 Coreanos Zainichi são um grupo minoritário no Japão. São chamados de zainichi os imigrantes coreanos e seus descendentes que migraram para o Japão durante o domínio colonial japonês 
o governo japonês não adotou medidas transitórias para garantir a inclusão deste grupo após 1982 - são pessoas que não contribuíram para aposentadoria quando eram jovens e já não tinham idade para contribuir após a mudança da lei ${ }^{35}$.

No sétimo relatório periódico (JAPAN, 2014) da Convenção sobre a Eliminação de Todas as Formas de Discriminação contra a Mulher (CEDAW), o governo japonês destacou o estabelecimento de esforços para a promoção da igualdade de gênero nas políticas de promoção de qualidade de vida para idosos - como emprego, participação social e presentes no Terceiro Plano para Igualdade de Gênero (2010) do país. O comitê, por sua vez, levantou preocupações acerca dos preconceitos sociais existentes contra a mulher idosa no país, existência de piores índices educacionais entre as mulheres idosas de minorias étnicas como Ainu e Buraku e sobre o fenômeno da "feminização da pobreza".

Por fim, no primeiro relatório periódico da Convenção sobre os Direitos das Pessoas com Deficiência (CRPD), o governo destacou medidas de (i) conscientização e acessibilidade que beneficiam os idosos em suas iniciativas que promovem o design universal em hardwares, softwares e nos sistemas de transporte; (ii) medidas preventivas para atender melhor às populações vulneráveis como os idosos em situações de emergência, (iii) acesso à justiça por meio de serviços de aconselhamento legal e advogados na residência ou em centros de idosos (JAPAN, 2017). Não havia considerações por parte do Comitê da CRPD sobre esses pontos até a conclusão deste texto.

Em suma, é possível apreender, por meio da análise dos referidos documentos, que a comunidade internacional reconhece, por um lado, a existência de uma amplitude de direitos e proteções específicas a uma grande parcela da população idosa no Japão - e que tais direitos são promovidos por diversas políticas públicas existentes - e por outro, que há uma lacuna significativa de proteção referente à população idosa que faz parte de grupos mais vulneráveis como mulheres, minorias étnicas, população de baixa renda e em situações de emergências.

\section{Considerações finais}

A percepção sobre os idosos, seu papel na sociedade e seus direitos mudou significativamente desde a segunda metade do Século XX tanto na comunidade internacional quanto em estados nacionais como o Japão. O sistema internacional não está mais alheio às necessidades dos idosos enquanto grupo que necessita de mecanismos de promoção e proteção de direitos específicos para que possam exercer plenamente suas liberdades

(1910-1945) voluntariamente ou recrutados pelo governo e serviço militar japonês. (CARVALHO; YAMAMOTO, 2018)

35 A Associação de Advogados de Coreanos "Zainichi” apresentou um relatório na 85a Sessão do Comitê para a Eliminação da Discriminação Racial denunciando tal pratica do governo como discriminatória. Para maiores informações ver(LAWYERS ASSOCIATION OF ZAINICHI KOREANS (LAZAK), 2014) disponível em < https://tbinternet.ohchr.org/Treaties/CERD/Shared\%20Documents/JPN/INT_ CERD_NGO_JPN_17768_E.pdf $>$ Acesso em: 25/11/2019. 
fundamentais. Embora seus instrumentos de proteção estejam fragmentados em diferentes documentos, é possível utilizá-los para monitorar e pressionar os Estados a tomarem medidas adequadas para protegê-los.

Neste cenário, o Japão se destaca não apenas pela proporção de idosos que possui em sua sociedade, como também pela forma como vem respondendo aos desafios que uma transformação demográfica tão acelerada apresentou à nação. Do ponto de vista dos direitos humanos, o país introduziu muitos mecanismos de promoção e proteção dos direitos dos idosos, entre os quais se destacam o Sistema de Seguro de Cuidados de Longa Duração e a Lei Básica sobre Medidas para a Sociedade em Envelhecimento. Ambas as medidas têm como objetivo preparar a sociedade para o envelhecimento, respeitando o direito dos idosos em manter-se parte de suas comunidades. Contudo, a partir do processo de monitoramento internacional sobre os pactos ratificados pelo país, torna-se evidente a existência de lacunas na garantia dos direitos de idosos pertencentes a grupos minoritários - notadamente as mulheres, minorias étnicas e a população de baixa renda. É urgente que o governo japonês tome medidas para suprir tais lacunas e, nesse ponto, o sistema internacional tem um papel fundamental de influência e pressão junto ao governo.

\section{Referências Bibliográficas}

ASIA PACIFIC OBSERVATORY. Japan Health System Review. [s.l: s.n.].

CARVALHO, B. A.; YAMAMOTO, L. Discrimination and hate speech against North Korean Schools in Japan. Estudos Japoneses, v. 39, p. 125-136, 2018.

CEDAW. Convention on the Elimination of All Forms of Discrimination against Women, 1979. Disponível em: <https://www.ohchr.org/Documents/ProfessionalInterest/cedaw. pdf $>$. Acesso em: 25 nov. 2019

CESCR. International Covenant on Economic, Social and Cultural Rights, 1966. Disponível em: <https://www.ohchr.org/Documents/ProfessionalInterest/cescr.pdf>. Acesso em: 25 nov. 2019

CESCR. General Comment No. 6: The Economic, Social and Cultural Rights of Older Persons, 1995. Disponível em: <https://www.refworld.org/pdfid/4538838f11.pdf >. Acesso em: 25 nov. 2019

CESCR. Concluding observations on the third periodic report of Japan, adopted by the Committee at its fiftieth session. [s.1: s.n.].

CRPD. Convention on the Rights of Persons with Disabilities and Optional Protocol UNITED NATIONS, 2006. Disponível em: <https://www.un.org/disabilities/documents/convention/ convoptprot-e.pdf>. Acesso em: 25 nov. 2019

DEBERT, G. G. Família, Classe Social e Etnicidade: Um Balanço da Bibliografia sobre a Experiência de Envelhecimento. BiB - Boletim Informativo e Bibliográfico, n. 33, p. 33-50, 1992. 
DESA. World Population Prospects The 2017 Revision. United Nations, Department of Economic and Social Affairs, Population Division: [s.n.]. Disponível em: <https://population. un.org/wpp/Publications/Files/WPP2017_KeyFindings.pdf>. Acesso em: 25 nov. 2019.

ETO, M. Public Involvement in Social Policy Reform: Seen from the Perspective of Japan's Elderly-Care Insurance Scheme. Journal of Social Policy, v. 30, n. 1, p. 17-36, 2001.

FREDVANG, M.; BIGGS, S. The rights of older persons: Protection and gaps under human rights law. Social Policy Working Paper, n. 16, p. 1-21, 2012.

HASHIMOTO, A. The Gift of Generations: Japanese and American Perspectives on Aging and the Social Contract. Cambridge: Cambridge University Press, 2009.

ICCPR. International Covenant on Civil and Political Rights16 December 1966, (entry into force 23 March 1976), 1966. Disponível em: <https://www.ohchr.org/en/professionalinterest/ pages/ccpr.aspx>. Acesso em: 25 nov. 2019

ICPRMMF. International Convention on the Protection of the Rights of All Migrant Workers and Members of Their Families, 1990. Disponível em: <https://www.ohchr.org/EN/ ProfessionalInterest/Pages/CMW.aspx>. Acesso em: 25 nov. 2019

JAPAN. CABINET OFFICE. Annual Report on the Ageing Society. [s.1: s.n.]. Disponível em: $<$ https://www8.cao.go.jp/kourei/english/annualreport/2017/pdf/c1-1.pdf $>$. Acesso em: 25 nov. 2019

JAPAN. NIPSSR. Population and Social Security in Japan. [s.l: s.n.]. Disponível em: < http:// www.ipss.go.jp/s-info/e/pssj/pssj2019.pdf>. Acesso em: 25 nov.2019

JAPAN. Third periodic reports submitted by States parties under articles 16 and 17 of the Covenant. CESCR: [s.n.]. Disponível em: <https://tbinternet.ohchr.org/_layouts/15/ treatybodyexternal/Download.aspx?symbolno=E\%2FC.12\%2FJPN\%2F3\&Lang=en $>$. Acesso em 25 nov. 2019

JAPAN. Sixth periodic International Covenant on Civil and Political Rights. CCPR: [s.n.].

JAPAN. Seventh and eighth periodic reports of Convention on the Elimination of All Forms of Discrimination Against Women : fourth periodic reports of states parties : Colombia. CEDAW: [s.n.].

JAPAN. Initial report submitted by Japan under article 35 of the Convention. CRPD: [s.n.].

KANTER, A. S. The United Nations Convention on the Rights of Persons with Disabilities and its Implications for the Rights of Elderly People Under International Law. 2009.

LAWYERS ASSOCIATION OF ZAINICHI KOREANS (LAZAK). Discrimination Against Koreans in Japan : Japan's Violation of the International Convention on the Elimination of All Forms of Racial Table of Contents. [s.l: s.n.]. Disponível em: <https://tbinternet.ohchr.org/Treaties/CERD/Shared Documents/JPN/INT_CERD_NGO_JPN_17768_E. pdf>. Acesso em 21 nov. 2019

MHLW JAPAN. Report of the Study Group for Japan's International Contribution to 'Active Aging' (Original in Japanese) International Affairs Division Minister's 
Secretariat Ministry of Health, Labour, and Welfare of Japan. [s.l: s.n.]. Disponível em: <https:/www.mhlw.go.jp/file/05-Shingikai-10501000-Daijinkanboukokusaika-Kokusaika/0000044929.pdf $>$.

MINISTRY OF HEALTH LABOUR AND WELFARE OF JAPAN. Long-Term Care Insurance System of Japan. [s.1: s.n.]. Disponível em: <https://www.mhlw.go.jp/english/policy/ care-welfare/care-welfare-elderly/dl/ltcisj_e.pdf $>$.

MIPAA. Plano de Ação Internacional sobre o Envelhecimento (Organização das Nações Unidas. tradução de Arlene Santos, Ed.)BrasíliaSecretaria Especial dos Direitos Humanos, 2003, 2002.

NAÇÕES UNIDAS. Declaração Universal dos Direitos Humanos, 1948. Disponível em: $<$ https://nacoesunidas.org/direitoshumanos/declaracao/>. Acesso em: 25 nov. 2019

NAÇÕES UNIDAS BRASIL. O que são direitos humanos | ONU Brasil. Disponível em: $<$ https://nacoesunidas.org/direitoshumanos/>. Acesso em: 21 nov. 2019a.

NAÇÕES UNIDAS BRASIL. Pessoas idosas | ONU Brasil. Disponível em: < https://nacoesunidas.org/acao/pessoas-idosas/>. Acesso em: 21 nov. $2019 \mathrm{~b}$.

OCDE. Poverty risks in old-age remains high Shift of poverty risks across generations at different ages in Japan. p. 75-76, 2017.

OHCHR \& UNDESA. Human rights of older persons References from some core international human rights treaties and the Madrid International Plan of Action on Ageing Office of the High Commissioner for Human Rights and Department on Economic and Social Affairs. [s.l: s.n.]. Disponível em: <https://social.un.org/ageing-working-group/ documents/Table HR \& MIPAA - April 2011.pdf>. Acesso em 21 nov. 2019

RODRIGUEZ-PINZÓN, D. The International Human Rights Status of Elderly Persons. American University International Law Review, v. 18, n. 4, p. 915-1008, 2003.

USUI, C.; PALLEY, H. A. The Development of Social Policy for the Elderly in Japan. Social Service Review, v. 71, n. 3, p. 360-381, 1997. 


\section{Anexo 1}

A tabela a seguir contém algumas referências das disposições existentes nos principais tratados de direitos humanos e no MIPAA sobre o envelhecimento e a relação de leis do Japão referentes aos mesmos temas. A seleção não é exaustiva.

Lista de siglas citadas na tabela:

- CEDAW: Convenção para Eliminação de Todas as Formas de Discriminação contra a Mulher;

- Convention on the Elimination of All forms of Discrimination Against Women (1979).

- CEDAW GR 27: Comitê para Eliminação de Todas as Formas de Discriminação contra a Mulher, General Recommendation No.27 on the rights of older women, CEDAW/C/2010/47/GC.1, 19 October 2010

- CESCR GC 6: Comitê sobre Direitos Econômicos, Sociais e Culturais (Committee on Economic, Social and Cultural Rights), General Comment No.6 on the economic, social and cultural rights of older persons - 12/08/1995

- CESCR GC 19: Comitê sobre Direitos Econômicos, Sociais e Culturais, General Comment No.19 on the right to social security (art. 9) - E/C.12/GC/19, 4 February 2008

- CESCR GC 20: Comitê sobre Direitos Econômicos, Sociais e Culturais, General Comment No.20 on Non-Discrimination in Economic, Social and Cultural Rights (art. 2, para. 2) - E/C.12/GC/20, 10 June 2009

- CRPD: Convenção sobre os Direitos das Pessoas com Deficiência (Convention on the Rights of Persons with Disabilities) (2006)

- PIDCP: Pacto Internacional de Direitos Civis e Políticos (1966)

- PIDESC: Pacto Internacional dos Direitos Econômicos, Sociais e Culturais (1966)

- MIPAA: Plano de Ação Internacional sobre o Envelhecimento de Madri (Madrid Plan of Action on Ageing) (2002) 


\begin{tabular}{|c|c|c|c|c|}
\hline $\begin{array}{l}\text { Direitos } \\
\text { Humanos }\end{array}$ & $\begin{array}{l}\text { Principais } \\
\text { tratados } \\
\text { internacionais } \\
\text { de DHs }\end{array}$ & $\begin{array}{l}\text { Comentários } \\
\text { gerais ou } \\
\text { recomendações } \\
\text { gerais dos órgãos } \\
\text { de tratados de } \\
\text { direitos humanos }\end{array}$ & $\begin{array}{l}\text { Instruções } \\
\text { prioritárias no } \\
\text { Plano de Ação } \\
\text { Internacional } \\
\text { de Madri para o } \\
\text { Envelhecimento }\end{array}$ & $\begin{array}{l}\text { Leis e políticas } \\
\text { no Japão }\end{array}$ \\
\hline $\begin{array}{l}\text { 1. Igualdade e } \\
\text { não discrimi- } \\
\text { nação } \\
\text { Declaração uni- } \\
\text { versal dos direi- } \\
\text { tos humanos } \\
\text { art. 2: } \\
\text { Todos têm direito } \\
\text { a todos os direi- } \\
\text { tos e liberdades } \\
\text { estabelecidos } \\
\text { nesta Declaração, } \\
\text { sem qualquer } \\
\text { distinção }\end{array}$ & $\begin{array}{l}\text { ICCPR, art 2; } \\
\text { PIDESC, arts. } 2.2 \\
\text { e 3: Respeito e } \\
\text { garantia a todos } \\
\text { os direitos reco- } \\
\text { nhecidos no Pacto } \\
\text { sem distinção de } \\
\text { qualquer tipo. / - } \\
\text { Direitos iguais de } \\
\text { homens e mulheres. } \\
\text { /CEDAW, arts } \\
\text { 2: Eliminação de } \\
\text { Todas as Formas } \\
\text { de Discriminação } \\
\text { contra a Mulher } \\
\text { /CRPD art } 8.1: \\
\text { combater estereóti- } \\
\text { pos e preconceitos } \\
\text { relativos a pessoas } \\
\text { com deficiência (...) } \\
\text { incluindo idade. }\end{array}$ & $\begin{array}{l}\text { CESCR CG 6, } \\
\text { parágrafos 20-21: } \\
\text { - Em relação ao art. } \\
\text { 3, Estados devem } \\
\text { prestar atenção } \\
\text { especial a mulheres } \\
\text { mais velhas. } \\
\text { CESCR CG 20, } \\
\text { parágrafo 29: é } \\
\text { proibida discrimi- } \\
\text { nação por idade em } \\
\text { vários contextos }\end{array}$ & $\begin{array}{l}\text { OP I: Tema 8. Obj. } \\
\text { 1: Igualdade de } \\
\text { acesso de pessoas } \\
\text { idosas à alimenta- } \\
\text { ção, à moradia, à } \\
\text { assistência médica } \\
\text { e a outros serviços } \\
\text { durante e depois de } \\
\text { desastres naturais e } \\
\text { outras situações de } \\
\text { calamidade pública. }\end{array}$ & $\begin{array}{l}\text { Lei Básica sobre } \\
\text { Medidas para a } \\
\text { Sociedade em } \\
\text { Envelhecimento } \\
\text { (1995); A Lei } \\
\text { Básica para Pes- } \\
\text { soas com Defi- } \\
\text { ciência (2011), } \\
\text { Terceiro plano } \\
\text { básico para } \\
\text { igualdade de } \\
\text { gênero (2010); } \\
\text { A Lei Básica de } \\
\text { Contramedidas } \\
\text { de Desas- } \\
\text { tres (2013) }\end{array}$ \\
\hline $\begin{array}{l}\text { 2. Direito a um } \\
\text { padrão de vida } \\
\text { adequado } \\
\text { Declaração Uni- } \\
\text { versal de } \\
\text { Direitos huma- } \\
\text { nos, art.25: } \\
\text { Inclui comida, } \\
\text { roupas, habita- } \\
\text { ção, assistência } \\
\text { médica, servços } \\
\text { sociais neces- } \\
\text { sário doença, } \\
\text { incapacidade, } \\
\text { viuvez e velhice. }\end{array}$ & $\begin{array}{l}\text { PIDESC, art. } 11 \text { e } \\
\text { 2.2.: Inclui moradia } \\
\text { adequada, comida } \\
\text { e roupas, e a con- } \\
\text { tínua melhoria das } \\
\text { condições de vida, } \\
\text { sem discrimina- } \\
\text { ção para idosos. / } \\
\text { CRPD, art. 28: } \\
\text { idem acima. E Ido- } \\
\text { sos com deficiência } \\
\text { devem ter acesso a } \\
\text { redes de proteção e } \\
\text { programas de redu- } \\
\text { ção da pobreza. / } \\
\text { CEDAW, art. 14.2 } \\
\text { h) condições ade- } \\
\text { quadas para mulhe- } \\
\text { res de zona rural }\end{array}$ & $\begin{array}{l}\text { CESCR CG } 6 \\
\text { pára. 30: fornecer } \\
\text { benefícios não } \\
\text { contributivos para } \\
\text { a velhice / pára. } \\
\text { 33: devem ajudar } \\
\text { idosos a continuar } \\
\text { vivendo em suas } \\
\text { próprias casas. } \\
\text { CEDAW GR 27, } \\
\text { pars. } 43 \text { e 44: Os } \\
\text { fornecer a todas } \\
\text { as mulheres um } \\
\text { número não con- } \\
\text { tributivo adequado } \\
\text { de pensões (em } \\
\text { igualdade de condi- } \\
\text { ções com homens); } \\
\text { / que sejam aces- } \\
\text { síveis a mulheres } \\
\text { mais velhas }\end{array}$ & $\begin{array}{l}\text { OP I: Tema 3: OBj } \\
\text { 1,2 e3: melhoria } \\
\text { de vida de pessoas } \\
\text { idosas nas zonas } \\
\text { rurais. / Tema 6, } \\
\text { obj 1: redução de } \\
\text { pobreza entre ido- } \\
\text { sos/ Tema 7, oj 2: } \\
\text { Renda mínima sufi- } \\
\text { ciente para idosos/ } \\
\text { tema 8, obj 1: acesso } \\
\text { dos idosos a bens e } \\
\text { serviços após emer- } \\
\text { gências/ OI2: Tema } \\
\text { 1, obj 3: acesso a } \\
\text { alimentos e nutrição } \\
\text { para idosos OI3: } \\
\text { tema 1, objs 1,2 e 3: } \\
\text { envelhecer em casa, } \\
\text { melhoria de habi- } \\
\text { tação, preços aces- } \\
\text { síveis, transportes } \\
\text { acessíveis para idoso }\end{array}$ & $\begin{array}{l}\text { Lei de Serviço } \\
\text { de Bem-Estar } \\
\text { Social para os } \\
\text { Idosos (1963); } \\
\text { Sistema Univer- } \\
\text { sal de Seguros } \\
\text { de Saúde e Pre- } \\
\text { vidência (1961); } \\
\text { Sistema de } \\
\text { Seguro de Cui- } \\
\text { dados de Longa } \\
\text { Duração (2000); } \\
\text { Revisão da Lei } \\
\text { de Garantia do } \\
\text { Abastecimento } \\
\text { Estável de } \\
\text { Moradias para } \\
\text { Idosos (2011); } \\
\text { Lei de Saúde } \\
\text { para o Idoso } \\
\text { - com aconse- } \\
\text { lhamento nutri- } \\
\text { cional; Public } \\
\text { Assistance Act; } \\
\text { A lei de promo- } \\
\text { ção do trans- } \\
\text { porte tranquilo. }\end{array}$ \\
\hline
\end{tabular}




\begin{tabular}{|c|c|c|c|c|}
\hline $\begin{array}{l}\text { Direitos } \\
\text { Humanos }\end{array}$ & $\begin{array}{l}\text { Principais } \\
\text { tratados } \\
\text { internacionais } \\
\text { de DHs }\end{array}$ & $\begin{array}{l}\text { Comentários } \\
\text { gerais ou } \\
\text { recomendações } \\
\text { gerais dos órgãos } \\
\text { de tratados de } \\
\text { direitos humanos }\end{array}$ & $\begin{array}{l}\text { Instruções } \\
\text { prioritárias no } \\
\text { Plano de Ação } \\
\text { Internacional } \\
\text { de Madri para o } \\
\text { Envelhecimento }\end{array}$ & $\begin{array}{l}\text { Leis e políticas } \\
\text { no Japão }\end{array}$ \\
\hline $\begin{array}{l}\text { 3. Direito ao } \\
\text { mais alto atin- } \\
\text { gível } \\
\text { padrão de físico } \\
\text { e saúde mental } \\
\text { Declaração Uni- } \\
\text { versal de } \\
\text { Direitos huma- } \\
\text { nos, art.25: O } \\
\text { direito a um } \\
\text { padrão de vida } \\
\text { adequado à saúde } \\
\text { e bem-estar de } \\
\text { todas as pessoas. }\end{array}$ & $\begin{array}{l}\text { PIDESC, art. 12: } \\
\text { Direito universal } \\
\text { ao gozo do mais } \\
\text { alto padrão possível } \\
\text { de saúde física e } \\
\text { mental/ CEDAW, } \\
\text { art. 12: - eliminar } \\
\text { discriminação } \\
\text { contra as mulhe- } \\
\text { res no campo dos } \\
\text { cuidados de saúde } \\
\text { / CRPD, art. 25 } \\
\text { b): garantir acesso } \\
\text { para pessoas } \\
\text { com deficiência } \\
\text { a serviços de } \\
\text { saúde e serviços } \\
\text { projetados para } \\
\text { minimizar e evitar } \\
\text { mais deficiência } \\
\text { incluindo idosos. }\end{array}$ & $\begin{array}{l}\text { CESCR CG 6, } \\
\text { pars. 34 e 35 e GC } \\
\text { 14, par. 25: abor- } \\
\text { dagem abrangente } \\
\text { e integrada com } \\
\text { prevenção, reabi- } \\
\text { litação e cuidados } \\
\text { dos doentes ter- } \\
\text { minais. / CEDAW } \\
\text { GR 27, parágrafos } \\
\mathbf{4 5} \text { e 45: política } \\
\text { específica para a } \\
\text { proteção da saúde } \\
\text { das mulheres mais } \\
\text { velhas, especial- } \\
\text { mente de mulheres } \\
\text { pertencentes a } \\
\text { minorias e mulhe- } \\
\text { res com deficiência. }\end{array}$ & $\begin{array}{l}\text { OPII: Tema } 1 \text { Objs } \\
\text { 1,2,3: políticas } \\
\text { de prevenção de } \\
\text { doenças, acesso a } \\
\text { alimentos e nutri- } \\
\text { ção adequadas. / } \\
\text { Tema 2, Objs 1,2,3 } \\
\text { e4: Eliminação } \\
\text { de desigualdades } \\
\text { sociais, incluindo } \\
\text { linguística, para } \\
\text { idosos terem acesso } \\
\text { a saúde; desenvol- } \\
\text { vimento de serviços } \\
\text { de atenção primária } \\
\text { e longo prazo com } \\
\text { participação dos } \\
\text { idosos/ Tema 3: obj } \\
\mathbf{1} \text { e 2: Avaliação de } \\
\text { impacto de HIV e } \\
\text { Aids na saúde dos } \\
\text { idosos e acesso a e } \\
\text { assistência médica. }\end{array}$ & $\begin{array}{l}\text { Sistema Univer- } \\
\text { sal de Seguros } \\
\text { de Saúde e } \\
\text { Previdência } \\
\text { (1961); Sistema } \\
\text { de Seguro de } \\
\text { Cuidados de } \\
\text { Longa Duração } \\
\text { (2000); Lei de } \\
\text { Saúde para o } \\
\text { Idoso - com } \\
\text { aconselhamento } \\
\text { nutricional; } \\
\text { Terceiro plano } \\
\text { básico para } \\
\text { igualdade de } \\
\text { gênero; A Lei } \\
\text { Básica para } \\
\text { Pessoas com } \\
\text { Deficiência }\end{array}$ \\
\hline $\begin{array}{l}\text { 4. Direito ao } \\
\text { trabalho } \\
\text { Declaração Uni- } \\
\text { versal de } \\
\text { Direitos huma- } \\
\text { nos, art. 23: } \\
\text { Direito universal } \\
\text { ao trabalho e } \\
\text { pagamento igual } \\
\text { por igual traba- } \\
\text { lho, sem nenhum } \\
\text { tipo } \\
\text { de discriminação }\end{array}$ & $\begin{array}{l}\text { PIDESC, arts. } 6 \\
\text { e 7: O direito de } \\
\text { todos à oportuni- } \\
\text { dade de ganhar a } \\
\text { vida por trabalho } \\
\text { que ele escolha } \\
\text { livremente, remu- } \\
\text { neração justa sem } \\
\text { qualquer tipo de } \\
\text { discriminação/ } \\
\text { programas de for- } \\
\text { mação técnica e } \\
\text { profissional orien- } \\
\text { tação e treinamento }\end{array}$ & $\begin{array}{l}\text { CESCR CG 6, } \\
\text { pars } 24 \text { a 25: } \\
\text { prevenir discri- } \\
\text { minação com } \\
\text { base na idade em } \\
\text { empregos/ empre- } \\
\text { gar trabalhadores } \\
\text { idosos onde melhor } \\
\text { aproveitem sua } \\
\text { experiência/ prepa- } \\
\text { ração para aposen- } \\
\text { tadoria/ CEDAW } \\
\text { CR 27, par. } 41 \\
\text { e 42: empregar } \\
\text { mulheres idosas } \\
\text { sem discriminação } \\
\text { com base na idade. }\end{array}$ & $\begin{array}{l}\text { OPI: Tema } 2 \text { obj } \\
\text { 1: oportunidade } \\
\text { de emprego todos } \\
\text { idosos que queiram } \\
\text { trabalhar/ Tema } 4 \\
\text { Obj1: treinamento e } \\
\text { recolocamento para } \\
\text { idosos/ OPII: tema } \\
\text { 6, obj 1: manuten- } \\
\text { ção da capacidade } \\
\text { funciona longo da } \\
\text { vida e participação } \\
\text { idosos com deficiên- } \\
\text { cia/ OPIII Tema } \\
\mathbf{4} \text { obj 1: Melhoria } \\
\text { do reconhecimento } \\
\text { público da produtivi- } \\
\text { dade e outras contri- } \\
\text { buições dos idosos. }\end{array}$ & $\begin{array}{l}\text { Revisão da Lei } \\
\text { de Estabilização } \\
\text { do Emprego } \\
\text { para Idosos } \\
\text { (2015); Lei } \\
\text { Básica sobre } \\
\text { Medidas para a } \\
\text { Sociedade em } \\
\text { Envelhecimento } \\
\text { (1995); Centro } \\
\text { de Recursos } \\
\text { Humanos } \\
\text { Prateado }\end{array}$ \\
\hline
\end{tabular}




\begin{tabular}{|c|c|c|c|c|}
\hline $\begin{array}{l}\text { Direitos } \\
\text { Humanos }\end{array}$ & $\begin{array}{l}\text { Principais } \\
\text { tratados } \\
\text { internacionais } \\
\text { de DHs }\end{array}$ & $\begin{array}{l}\text { Comentários } \\
\text { gerais ou } \\
\text { recomendações } \\
\text { gerais dos órgãos } \\
\text { de tratados de } \\
\text { direitos humanos }\end{array}$ & $\begin{array}{l}\text { Instruções } \\
\text { prioritárias no } \\
\text { Plano de Ação } \\
\text { Internacional } \\
\text { de Madri para o } \\
\text { Envelhecimento }\end{array}$ & $\begin{array}{l}\text { Leis e políticas } \\
\text { no Japão }\end{array}$ \\
\hline $\begin{array}{l}\text { 5. Direito a } \\
\text { segurança social } \\
\text { Declaração Uni- } \\
\text { versal de Direitos } \\
\text { humanos, } \\
\text { art. 22: O direito } \\
\text { a segurança } \\
\text { social; } \\
\text { A realização de } \\
\text { direitos econô- } \\
\text { mico, social e } \\
\text { culturais indis- } \\
\text { pensáveis para } \\
\text { dignidade do } \\
\text { ser humano. }\end{array}$ & $\begin{array}{l}\text { PIDESC, art. 9: o } \\
\text { direito à segurança } \\
\text { social, } \\
\text { incluindo seguro } \\
\text { social. / CEDAW, } \\
\text { art. 11.1 e): Igual- } \\
\text { dade entre homens } \\
\text { e mulheres à } \\
\text { seguridade social, } \\
\text { principalmente nos } \\
\text { casos de aposenta- } \\
\text { doria, desemprego, } \\
\text { doença, invalidez } \\
\text { e velhice. / CDPD, } \\
\text { art. 28.2: Pessoas } \\
\text { idosas com defi- } \\
\text { ciência: devem ter } \\
\text { acesso a programas } \\
\text { de proteção social e } \\
\text { redução da pobreza }\end{array}$ & $\begin{array}{l}\text { CESCR GC 6, } \\
\text { pars. 26 a 30: ofe- } \\
\text { recer benefícios de } \\
\text { velhice não contri- } \\
\text { butivos a todos os } \\
\text { idosos / Idade da } \\
\text { aposentadoria deve } \\
\text { ser flexível CESCR } \\
\text { GC 19, par. 15: } \\
\text { seguridade social } \\
\text { para os idosos. / } \\
\text { CEDAW CR 27, } \\
\text { par. } \mathbf{4 2 ,} \mathbf{4 3} \text { e 44: } \\
\text { Pensões não contri- } \\
\text { butivas para todas } \\
\text { as mulheres (igual- } \\
\text { dade de condições } \\
\text { com os homens). }\end{array}$ & $\begin{array}{l}\text { OPI: Tema } 5 \text { Obj } \\
\text { 1: solidariedade e } \\
\text { reciprocidade entre } \\
\text { gerações/ Tema } 6 \\
\text { Obj 1: Redução da } \\
\text { pobreza entre ido- } \\
\text { sos/ Tema 7: Obj } \\
\text { 1 e 2: - programas } \\
\text { de proteção social } \\
\text { básica, incluindo, } \\
\text { pensões, seguro de } \\
\text { invalidez e bene- } \\
\text { fícios de saúde./ } \\
\text { Renda mínima sufi- } \\
\text { ciente para todos os } \\
\text { idosos, prestando } \\
\text { atenção especial } \\
\text { a grupos desfavo- } \\
\text { recidos social e } \\
\text { economicamente. }\end{array}$ & $\begin{array}{l}\text { Lei de Serviço } \\
\text { de Bem-Estar } \\
\text { Social para os } \\
\text { Idosos (1963); } \\
\text { Sistema Univer- } \\
\text { sal de Seguros } \\
\text { de Saúde e } \\
\text { Previdência } \\
\text { (1961);Public } \\
\text { Assistance Act; } \\
\text { Revisão da pre- } \\
\text { vidência } 2004\end{array}$ \\
\hline $\begin{array}{l}\text { 6. Direito à edu- } \\
\text { cação } \\
\text { Declaração } \\
\text { Universal dos } \\
\text { Direitos Huma- } \\
\text { nos, art. 26: - A } \\
\text { educação técnica } \\
\text { e profissional } \\
\text { deve estar dispo- } \\
\text { nível - A educa- } \\
\text { ção superior deve } \\
\text { estar igualmente } \\
\text { disponível para } \\
\text { todos (com base } \\
\text { no mérito) }\end{array}$ & $\begin{array}{l}\text { PIDESC art. 13 } \\
\text { e 6.2: Direito à } \\
\text { educação; políticas } \\
\text { de orientação e } \\
\text { treinamento téc- } \\
\text { nico e vocacional } \\
\text { CEDAW, art. 10: } \\
\text { eliminar a discri- } \\
\text { minação contra as } \\
\text { mulheres no campo } \\
\text { da educação, } \\
\text { acesso a programas } \\
\text { de educação conti- } \\
\text { nuada e de adultos. } \\
\text { CRPD, art. 24: } \\
\text { sistema educacio- } \\
\text { nal inclusivo e a } \\
\text { aprendizagem ao } \\
\text { longo da vida. }\end{array}$ & $\begin{array}{l}\text { CESCR CG 6, } \\
\text { pars. 36 e 37: } \\
\text { direito dos idosos } \\
\text { a educação; e } \\
\text { disponibilizar o } \\
\text { conhecimento dos } \\
\text { idosos para as gera- } \\
\text { ções mais jovens. / } \\
\text { (programas infor- } \\
\text { mais, comunitários } \\
\text { e de recreação para } \\
\text { idosos) / CEDAW } \\
\text { GR 27, par. 40. } \\
\text { garantir às mulhe- } \\
\text { res mais velhas o } \\
\text { acesso à educa- } \\
\text { ção de adultos. }\end{array}$ & $\begin{array}{l}\text { OPI:Tema } 4 \text { / Obj. } \\
1 \text { e 2: } \\
\text { Igualdade de } \\
\text { oportunidades na } \\
\text { educação, reci- } \\
\text { clagem e serviços } \\
\text { de colocação. / } \\
\text { reconhecimento } \\
\text { dos benefícios do } \\
\text { aumento experiên- } \\
\text { cia com a idade. }\end{array}$ & $\begin{array}{l}\text { Lei Básica sobre } \\
\text { Medidas para a } \\
\text { Sociedade em } \\
\text { Envelhecimento } \\
\text { (1995); Terceiro } \\
\text { plano básico } \\
\text { para igualdade } \\
\text { de gênero; Cen- } \\
\text { tro de Recur- } \\
\text { sos Humanos } \\
\text { Prateado. }\end{array}$ \\
\hline
\end{tabular}




\begin{tabular}{|c|c|c|c|c|}
\hline $\begin{array}{l}\text { Direitos } \\
\text { Humanos }\end{array}$ & $\begin{array}{l}\text { Principais } \\
\text { tratados } \\
\text { internacionais } \\
\text { de DHs }\end{array}$ & $\begin{array}{l}\text { Comentários } \\
\text { gerais ou } \\
\text { recomendações } \\
\text { gerais dos órgãos } \\
\text { de tratados de } \\
\text { direitos humanos }\end{array}$ & $\begin{array}{l}\text { Instruções } \\
\text { prioritárias no } \\
\text { Plano de Ação } \\
\text { Internacional } \\
\text { de Madri para o } \\
\text { Envelhecimento }\end{array}$ & $\begin{array}{l}\text { Leis e políticas } \\
\text { no Japão }\end{array}$ \\
\hline $\begin{array}{l}\text { 7. Direito à } \\
\text { privacidade } \\
\text { Declaração Uni- } \\
\text { versal dos Direi- } \\
\text { tos Humanos, } \\
\text { art. 12: - Direito } \\
\text { à privacidade } \\
\text { (proteção contra } \\
\text { interferências } \\
\text { arbitrárias) }\end{array}$ & $\begin{array}{l}\text { PIDESC art. 17: } \\
\text { Direito à priva- } \\
\text { cidade (proteção } \\
\text { contra interferên- } \\
\text { cias arbitrárias } \\
\text { ou ilegais em sua } \\
\text { privacidade, famí- } \\
\text { lia, casa ou } \\
\text { correspondência) }\end{array}$ & & $\begin{array}{l}\text { OP III: Promo- } \\
\text { ção do envelhecer } \\
\text { na comunidade, } \\
\text { levando em conside- } \\
\text { ração as preferências } \\
\text { individuais e opções } \\
\text { de moradia a preços } \\
\text { acessíveis para ido- } \\
\text { sos. / promover uma } \\
\text { vida independente. }\end{array}$ & $\begin{array}{l}\text { Revisão da Lei } \\
\text { de Garantia } \\
\text { do Abasteci- } \\
\text { mento Estável } \\
\text { de Moradias } \\
\text { para Idosos } \\
\text { (2011); Revisão } \\
\text { do Sistema de } \\
\text { Seguro de Cui- } \\
\text { dados de Longa } \\
\text { Duração (2014) }\end{array}$ \\
\hline $\begin{array}{l}\text { 8. Direito à } \\
\text { liberdade e } \\
\text { segurança da } \\
\text { pessoa } \\
\text { Declaração Uni- } \\
\text { versal de } \\
\text { Direitos huma- } \\
\text { nos, arts.3 e 5: } \\
\text { - Direito à vida, } \\
\text { liberdade e segu- } \\
\text { rança - Proibição } \\
\text { de qualquer tipo } \\
\text { de tratamento } \\
\text { cruel, desumano } \\
\text { ou degradante }\end{array}$ & $\begin{array}{l}\text { PIDCP, art. 7: } \\
\text { Proibição de tor- } \\
\text { tura e de qualquer } \\
\text { tratamento cruel, } \\
\text { desumano ou } \\
\text { degradante. CRPD, } \\
\text { art. 16: Exigência } \\
\text { de assistência e } \\
\text { apoio sensíveis à } \\
\text { idade para pessoas } \\
\text { com deficiência e } \\
\text { suas famílias para } \\
\text { evitar exploração, } \\
\text { violência e abuso }\end{array}$ & $\begin{array}{l}\text { CEDAW GR 27, } \\
\text { pars. 33, 36 e 37: } \\
\text { fornecer a mulheres } \\
\text { idosas informações } \\
\text { sobre seus direi- } \\
\text { tos. Sensibilizar e } \\
\text { treinar autoridades } \\
\text { sobre questões de } \\
\text { gênero e que afe- } \\
\text { tem as mulheres } \\
\text { mais velhas. / eli- } \\
\text { minar estereótipos } \\
\text { negativos contra } \\
\text { mulheres idosas. }\end{array}$ & $\begin{array}{l}\text { OP I: Tema } 5 \text { Obj } \\
\text { 1. Solidariedade e } \\
\text { reciprocidade entre } \\
\text { gerações. OP III: } \\
\text { Tema } 3 \text { Obj. } 1 \text { e } \\
2 \text { - Eliminação de } \\
\text { todas as formas de } \\
\text { negligência, abuso e } \\
\text { violência de idosos. }\end{array}$ & $\begin{array}{l}\text { Lei sobre } \\
\text { prevenção de } \\
\text { abuso de idosos } \\
\text { (2005); Assis- } \\
\text { tência jurídica } \\
\text { em centros } \\
\text { para idosos } \\
\text { (Japan Legal } \\
\text { Support Cen- } \\
\text { ter); Terceiro } \\
\text { plano básico } \\
\text { para igualdade } \\
\text { de gênero }\end{array}$ \\
\hline
\end{tabular}




\begin{tabular}{|c|c|c|c|c|}
\hline $\begin{array}{l}\text { Direitos } \\
\text { Humanos }\end{array}$ & $\begin{array}{l}\text { Principais } \\
\text { tratados } \\
\text { internacionais } \\
\text { de DHs }\end{array}$ & $\begin{array}{l}\text { Comentários } \\
\text { gerais ou } \\
\text { recomendações } \\
\text { gerais dos órgãos } \\
\text { de tratados de } \\
\text { direitos humanos }\end{array}$ & $\begin{array}{l}\text { Instruções } \\
\text { prioritárias no } \\
\text { Plano de Ação } \\
\text { Internacional } \\
\text { de Madri para o } \\
\text { Envelhecimento }\end{array}$ & $\begin{array}{l}\text { Leis e políticas } \\
\text { no Japão }\end{array}$ \\
\hline $\begin{array}{l}\text { 9. Direito à vida } \\
\text { familiar } \\
\text { Declaração Uni- } \\
\text { versal dos Direi- } \\
\text { tos Humanos, art. } \\
16.3 \text { A família, } \\
\text { como unidade } \\
\text { fundamental da } \\
\text { sociedade, tem } \\
\text { direito à prote- } \\
\text { ção do Estado }\end{array}$ & $\begin{array}{l}\text { PIDESC, art. 10: } \\
\text { - A família deve } \\
\text { usufruir da maior } \\
\text { proteção e assis- } \\
\text { tência possíveis. }\end{array}$ & $\begin{array}{l}\text { CESCR CG 6, } \\
\text { par. 31: apoiar e } \\
\text { fortalecer a família } \\
\text { e ajudá-la a respon- } \\
\text { der à necessidade } \\
\text { dos membros ido- } \\
\text { sos. CEDAW CR } \\
\text { 27, pars. } 43 \text { e 51: } \\
\text { benefícios sociais } \\
\text { e econômicos para } \\
\text { mulheres mais } \\
\text { velhas que cuidam } \\
\text { de crianças, bem } \\
\text { como todo o apoio } \\
\text { necessário para } \\
\text { cuidado de pais ou } \\
\text { parentes idosos. / } \\
\text { revogar legislação } \\
\text { que discrimine } \\
\text { mulheres mais } \\
\text { velhas em casa- } \\
\text { mento, herança } \\
\text { e propriedade }\end{array}$ & $\begin{array}{l}\text { OP I: Tema } 5 \text { Obj } \\
\text { 1. Solidariedade } \\
\text { e reciprocidade } \\
\text { entre gerações. OP } \\
\text { III: Promoção do } \\
\text { envelhecer na comu- } \\
\text { nidade, levando } \\
\text { em consideração as } \\
\text { preferências indi- } \\
\text { viduais e opções de } \\
\text { moradia a preços } \\
\text { acessíveis para } \\
\text { idosos. / apoio para } \\
\text { cuidadores de idosos }\end{array}$ & $\begin{array}{l}\text { Sistema de } \\
\text { Seguro de Cui- } \\
\text { dados de Longa } \\
\text { Duração (2000); } \\
\text { Revisão da Lei } \\
\text { de Garantia do } \\
\text { Abastecimento } \\
\text { Estável de } \\
\text { Moradias para } \\
\text { Idosos (2011); } \\
\text { Lei Básica sobre } \\
\text { Medidas para } \\
\text { a Sociedade } \\
\text { em Envelheci- } \\
\text { mento (1995) }\end{array}$ \\
\hline
\end{tabular}

Fonte: elaborada a partir de (OHCHR \& UNDESA, 2011) disponível em: https://social.un.org/ageing-working-group/documents/Table $\% 20 \mathrm{HR} \% 20$ \&\%20MIPAA\%20-\%20April\%202011.pdf Acesso em: 01/12/2019 